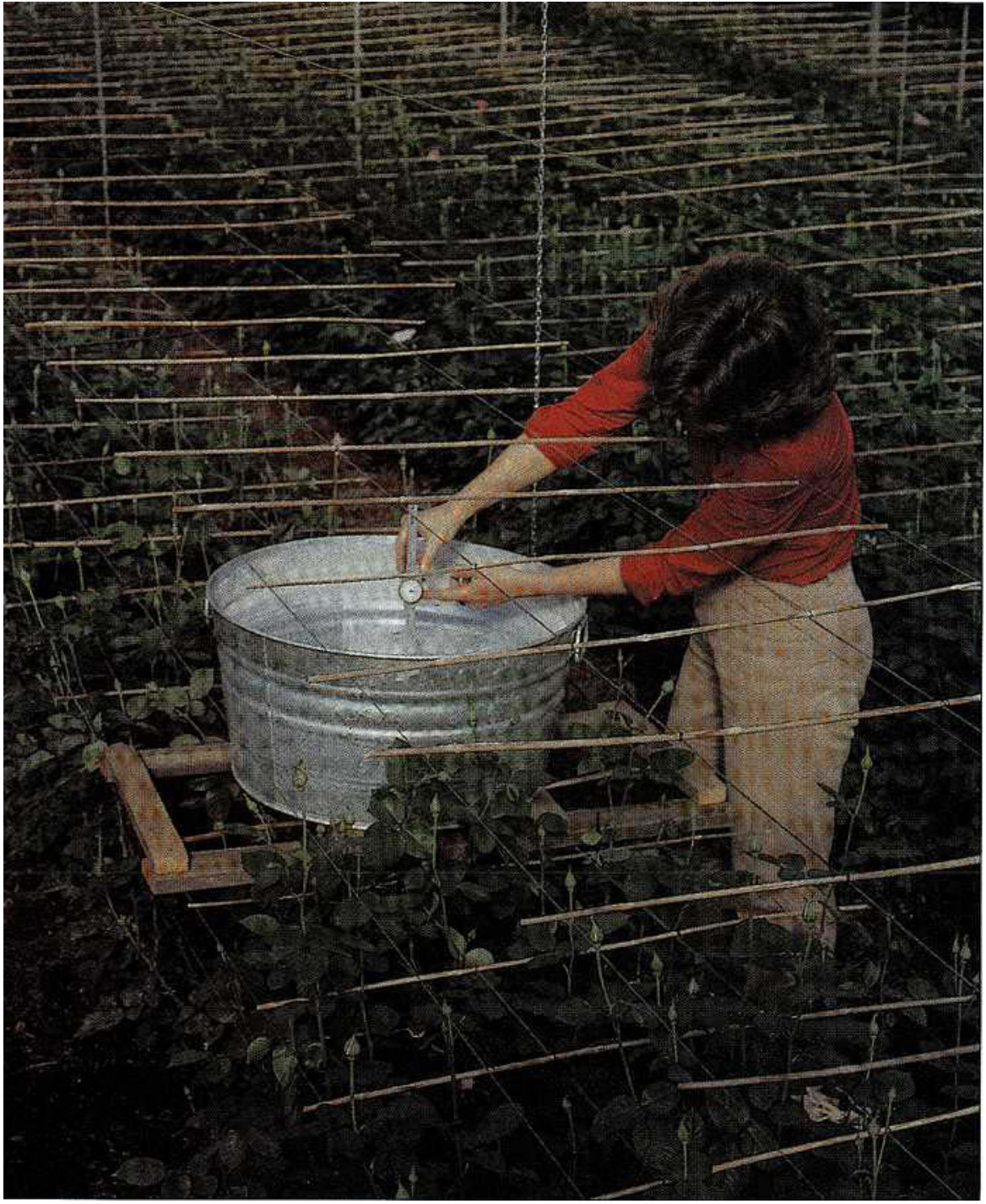

Evaporation pan scheduling. . .

\title{
How to reduce water use and maximize yields in greenhouse roses
}

\author{
Steve A. Tjosvold $\square$ Kurt F. Schulbach
}

\section{Evaporation pan scheduling can ac- curately predict the irrigation re- quirements of greenhouse roses. This simple system can be used by growers to minimize overirrigation while guarding against water stress that reduces yields.}

Valued at $\$ 90$ million in 1988, greenhousegrown roses are one of California's most beautiful and economically important crops. Most of these roses are produced in environmentally sensitive coastal areas of California where water is in short supply.
Greenhouse studies conducted during 1982-84 in the Pajaro Valley show that many growers do not irrigate frequently enough, and when they do irrigate, they apply too much water. The purpose of this research is to develop a simple irrigation scheduling system that can be used by rose growers to conserve water, reduce leaching of nitrates, and maximize yields.

One common scheduling system simply requires measuring the depth of water evaporated from a large pan placed near the top of the crop canopy. In our study, we used a No. 2 washtub, 22 inches in diameter and one foot deep. The inches of

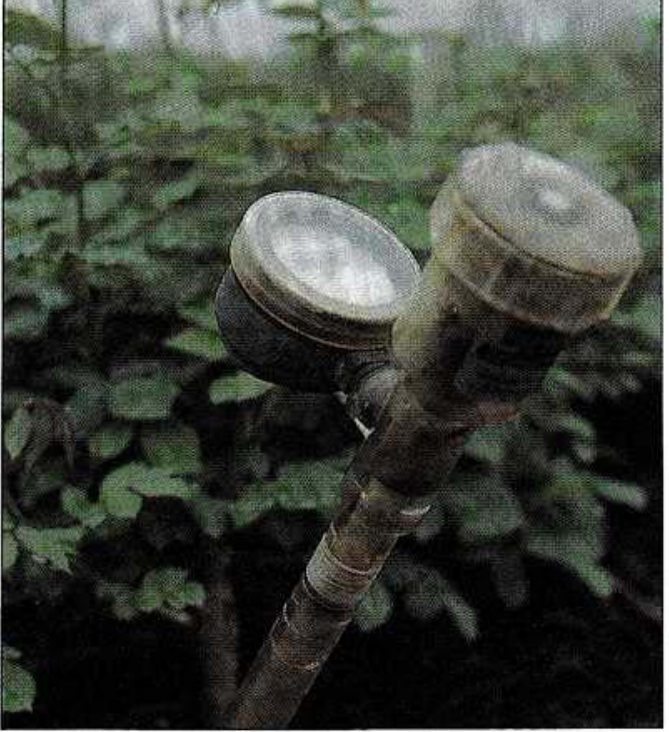

At left; the evaporation pan is placed near the top of the plant canopy so evaporation from the pan is not reduced by shading. It may be necessary to adjust the height of the pan as the crop grows. As shown above, each tensiometer is located in the center of the bed, its porous tip six inches deep.

water which evaporate from the pan are directly related to the amount of water used by the crop.

The relationship between pan evaporation and crop water use, called the "pan coefficient, "is variable and must be determined for different crops and different atmospheric conditions. We developed the pan coefficient for greenhouse grown roses by examining crop response under different amounts of irrigation. Once the coefficient is developed, pan evaporation is easily converted to gallons of water needed for irrigation.

\section{Procedure}

The experiments were conducted from 1985 through 1988 in a commercial greenhouse in Watsonville, California. We began with three irrigation treatments representing three different pan coefficients. Each treatment was replicated four times in a randomized complete block experimental design. The trial consisted of 12 beds (approximately 330 square feet per bed) of 'Royalty' roses; each bed being irrigated separately with measured amounts of water.

Soil moisture levels were monitored in each bed by tensiometers. A tensiometer consists of a closed tube with a vacuum gauge at the top and a porous ceramic tip at the bottom. The tube is filled with water and the ceramic tip is placed at the desired depth in the soil. As the soil dries, water is pulled out through the ceramic tip creating a partial vacuum that can be read on the gauge in centibars (cb). The gauge reading rises as the soil dries and gives a very good indication of water available to the crop.

An evaporation pan can give an accurate estimate of crop water use, but it does not directly provide information on how 
TABLE 1. Water stress levels and yields from the three irrigation treatments

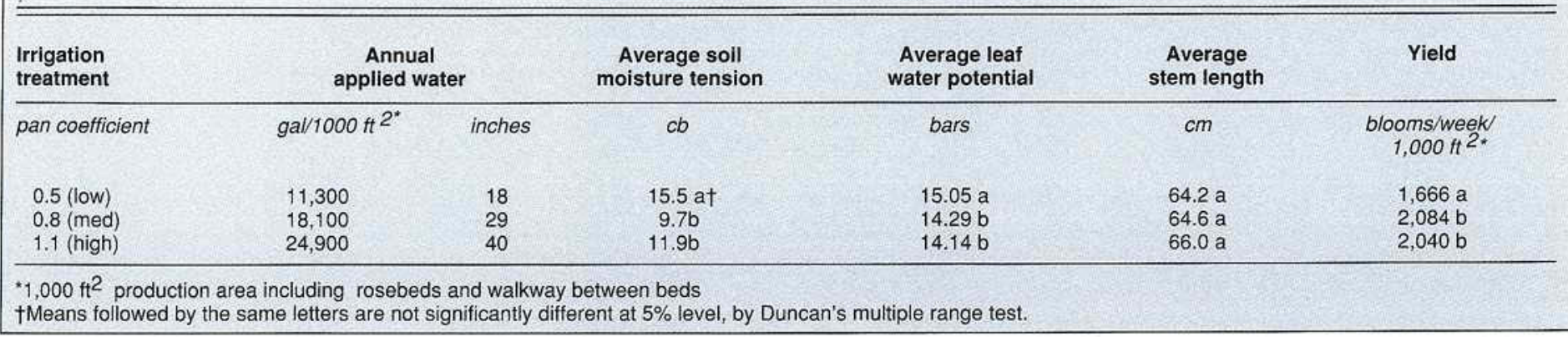

frequently irrigations should be applied. The interval between irrigations needs to be determined at first by using soil tension measurements. Other researchers have shown that for maximum rose production, soil moisture tensions should be kept below $10 \mathrm{cb}$. Therefore an irrigation is needed whenever the soil tension rises to $10 \mathrm{cb}$.

The time it takes for the tensiometer to reach $10 \mathrm{cb}$ varies depending on soil type and amount of water extracted by the crop. In our experiment, the interval was determined by the following procedure. The soil was thoroughly wetted, and the tensiometers were monitored until they reached an average of $10 \mathrm{cb}$. We then measured the evaporation from the pan and applied another thorough irrigation.

After several irrigation cycles, we determined that 0.3 inches of pan evaporation corresponded with the rise of the tensiometers to $10 \mathrm{cb}$. Having determined this interval, we could schedule irrigations by monitoring pan evaporation. Whenever 0.3 inches of water evaporated from the pan, it was time to irrigate. However, when using pan scheduling, it is a good idea to use tensiometers to check that irrigations are adequate.

Another very important factor to consider in any scheduling program is the uniformity of application of the irrigation system. In any system, some areas of the crop receive more water than others. If only the average irrigation requirement is applied, some areas will receive excess water and some areas will not receive enough. Some excess water above the crop requirement must be applied to the whole area to ensure that even the driest areas receive adequate water.

This required excess water is easy to calculate, but it requires measuring the uniformity of the irrigation system. We did this in our experiment by collecting and measuring water from various emitters spaced along the irrigation lines. The variability of discharge from each emitter determines the uniformity coefficient, which can be calculated in a number of different ways.
One common coefficient is called the emission uniformity (EU). It is calculated by dividing the average of the lowest $25 \%$. of the discharge measurements from the emitters by the average of all the measurements. The reciprocal of the EU is equivalent to the excess amount of water required. For example the EU in our experiment was 0.78 and $1 / 0.78=1.28$. In this case, $28 \%$ more water is required to adequately irrigate the driest areas.

The higher the EU, the less water is needed for an adequate irrigation. This is why it is so important to design and operate an irrigation system at maximum efficiency. A good maintenance program of cleaning and replacing emitters and flushing laterals is a very important part of water conservation.

To begin the experiment, we chose pan coefficients of $0.8,1.3$, and 1.8. These coefficients were then adjusted by dividing by the EU. This gave us adjusted coefficients for this experimental site of $1,1.7$, and 2.3 . For example, in the wettest treatment (2.3), when 0.3 inch of water was evaporated from the pan, $(2.3 \times 0.3)$, or 0.69 inches of water was applied to the appropriate plots.

\section{Results}

After 10 months of measurements, yield and soil moisture tensions showed no statistical difference between treatments, indicating that all treatments provided sufficient water. Since our purpose was to find the minimum irrigation level that produced no yield decrease, we continued the experiment with lower pan coefficients of $0.5,0.8$, and 1.1 (adjusted coefficients of $0.6,1.0$, and 1.4). These lower coefficients were followed for 12 months to ensure that they were constant during the different seasons of the year.

Before each irrigation, we collected soil tension data from each treatment. The 1.1 and 0.8 treatments were not statistically different but the 0.5 treatment had statistically higher readings. Although soil tensions in the 0.5 treatment averaged only about $5 \mathrm{cb}$ higher than the other treatments, yields were reduced by about $20 \%$.
Average stem lengths tended to increase in the wetter treatments, but were not statistically different. Leaf water potentials, which increase with water stress, were measured and showed results similar to the tensiometer data (table 1).

Throughout the 3 years of experiments, soil tensions were higher than expected. during the winter. Perhaps the pan coefficients underestimated water use during the winter. Possibly the winter heating with steam pipes on the ground caused soil evaporation that was not accounted for by the elevated evaporation pan. Some evidence also indicates that heating of the greenhouse may have resulted in increased water loss through the leaves by the roses at night. However, there was no indication of any yield reduction due to the higher soil tensions in winter. This could be due to the fact that water demand is lower in the winter and the plants weren't stressed at the higher soil tensions.

\section{Conclusions}

An evaporation pan is an excellent tool for scheduling irrigations in greenhouse roses. A pan coefficient of 0.8 , adjusted for the irrigation system's emission uniformity would be a good starting point with an adequate safety margin. This coefficient should be accurate throughout the year, but growers may want to raise it or decrease the irrigation interval during the winter.

When using evaporation pan scheduling to minimize water applications, soil salinity should be monitored monthly to guard against accumulation of salts. If salt accumulates, extra water should be applied to move salts just below the root zone, which is usually less than 24 inches deep. An additional advantage of irrigation scheduling is that it may be possible to reduce fertilizer applications because less fertilizer is carried below the root zone by overirrigation.

\footnotetext{
S. A. Tjosvold is Farm Advisor, Santa Cruz County; and K.F. Schulbach is Farm Advisor, Monterey County.
} 